Marketplace is provided as a service to readers using text and images from the manufacturer, supplier or distributor and does not imply endorsement by Vital. Normal and prudent research should be exercised before purchase or use of any product mentioned.

\section{FIGHT BAD BREATH}

Beverly Hills Formula Toothpaste from Purity Laboratories can remove tooth staining and offers maximum whitening power, while maintaining extremely low abrasion. The Total Protection is a dual action anti-bacterial formula to help fight plaque, tooth decay and bad breath.

The Sensitive formulation is designed for people who suffer from sensitive teeth, whilst the Breath Confidence fights bad breath for hours. The Natural with Aloe Vera and Echinacea offers natural gum protection, whitening power and no artificial colouring or flavours and its Gum Strengthening toothpaste fights gum disease by controlling the amount of plaque that builds up on your teeth.

Regular brushing with their latest whitening toothpaste will help nourish and strengthen gums, fight plaque, re-mineralise and harden tooth enamel for cavity protection and leave your breath smelling fresher. Beverly Hills Formula Gum Strengthening toothpaste contains ingredients that help reduce bleeding gums.

For further information visit www. beverlyhillsformula.com.
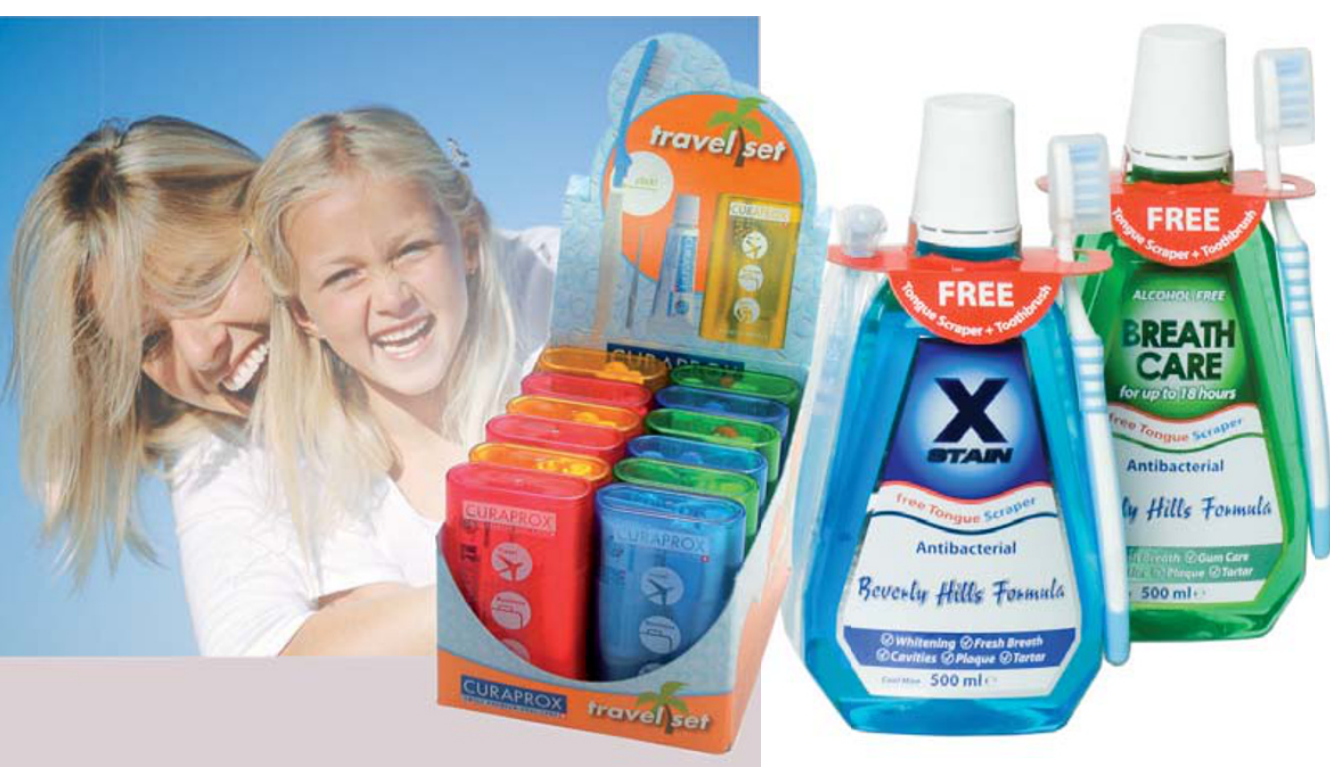

\section{BESPOKE PRACTICE VIDEOS}

A new service that produces video content especially for dentists for use either on their website or in the waiting area has been launched. JSP Media Group, headed by TV presenter Jemish Patel, will go to your practice and film a bespoke video for you to use in your practice waiting area, your website and/or to hand out as DVDs in your welcome packs.

The service can be used to promote and market the practice by using video marketing as a cost-effective solution to retain and attract new business, and can promote cosmetic, orthodontic or endodontic treatments to enable customers to have a much greater understanding of the practice's products and services.

For further information please visit www. jspmediagroup.com.

\section{HIGH PERFORMANCE SPRAY GEL}

Hu-Friedy has expanded its Enzymax detergent range to include the high-performance Spray $\mathrm{Gel}$ in the handy spray dispenser. This dualenzyme, $\mathrm{pH}$-neutral concentrate is an effective method for the pre-cleaning of dental instruments. Organic residues such as blood and proteins are effectively broken down by the enzymes. The eco-friendly Spray Gel is phosphate-free and biodegradable.

The new

Spray Gel

can make a

significant con-

tribution to prolonging

the life of dental

instruments.

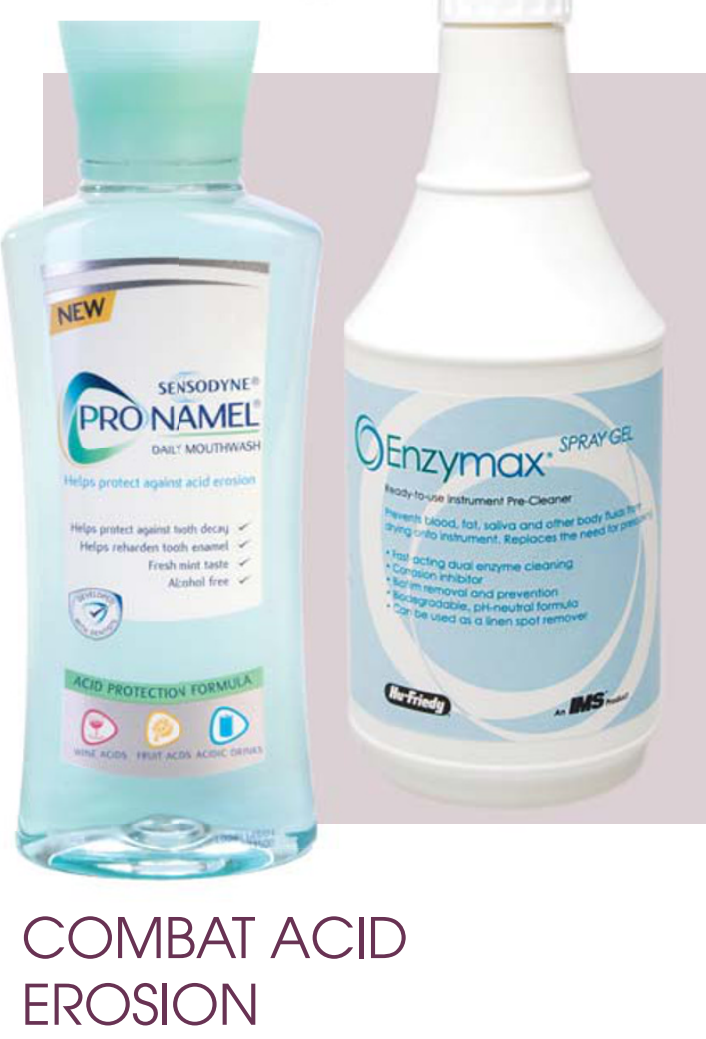

GlaxoSmithKline Consumer Healthcare (GSK) has recently launched new Sensodyne Pronamel Daily Mouthwash, designed to combat acid erosion. It includes Tri-Hydrapolymers, which can help build more protection against acid erosion than standard fluoride mouthwashes.

It can enhance delivery of fluoride to the tooth's surface, provide more protection against the effects of acid erosion compared to standard fluoride mouthwashes, and re-harden teeth to help protect against future acid challenges.

The full oral care product range includes Sensodyne, Corsodyl, Aquafresh and Poligrip. Samples of GSK's product range can be requested by visiting the dental professionals website www.gsk-dentalprofessionals.co.uk or alternatively by calling 08456000441 . 